NOTE

\title{
Visible absorption properties of radiation exposed XR type-T radiochromic film
}

\author{
Martin J Butson ${ }^{1,2}$, Tsang Cheung ${ }^{1}$ and Peter K N Yu ${ }^{1}$ \\ ${ }^{1}$ Department of Physics and Materials Science, City University of Hong Kong, Kowloon Tong, \\ Hong Kong \\ 2 Department of Medical Physics, Illawarra Cancer Care Centre, Crown St, Wollongong, \\ NSW 2500, Australia \\ E-mail: butsonm@iahs.nsw.gov.au
}

Received 30 June 2004

Published 20 September 2004

Online at stacks.iop.org/PMB/49/N347

doi:10.1088/0031-9155/49/19/N04

\begin{abstract}
The visible absorption spectra of Gafchromic XR type-T radiochromic film have been investigated to analyse the dosimetry characteristics of the film with visible light densitometers. Common densitometers can use photospectrometry, fluorescent light (broad-band visible), helium neon (632 nm), light emitting diode (LED) or other specific bandwidth spectra. The visible absorption spectra of this film when exposed to photon radiation show peaks at $676 \mathrm{~nm}$ and $618 \mathrm{~nm}$ at $2 \mathrm{~Gy}$ absorbed doses which shift to slightly lower wavelengths (662 $\mathrm{nm}$ and $612 \mathrm{~nm}$ at $8 \mathrm{~Gy}$ absorbed dose) at higher doses. This is similar to previous models of Gafchromic film such as MD-55-2 and HS but XR type-T also includes a large absorption at lower visible wavelengths due to 'yellow' dyes placed within the film to aid with visible recognition of the film exposure level. The yellow dye band pass is produced at approximately $520 \mathrm{~nm}$ to $550 \mathrm{~nm}$ and absorbs wavelengths lower than this value within the visible spectrum. This accounts for the colour change from yellow to brown through the added absorption in the red wavelengths with radiation exposure. The film produces a relatively high dose sensitivity with up to $0.25 \mathrm{OD}$ units per Gy change at $672 \mathrm{~nm}$ at $100 \mathrm{kVp}$ x-ray energy. Variations in dose sensitivity can be achieved by varying wavelength analysis.
\end{abstract}

\section{Introduction}

Radiochromic film dosimetry in radiation detection can depend on many parameters. Some of the major contributing factors can of course be the type of radiochromic film used, such as Gafchromic (ISP Technologies) (Butson et al 2003), Radiachromic (FWT Technologies) (Young et al 1999) or B3 windose (GEX Corporation) (Miller et al 2003). One of the largest 
contributing factors is the visible absorption spectra of the radiochromic film and as such the wavelength of readout. The absorption spectra for various types of films have been reported previously. This note reports the absorption spectra for a relatively new film, Gafchromic XR type-T film. XR type $\mathrm{T}$ has been specifically designed for analysis in the kilovoltage range with enhanced and relatively linear response in the $\mathrm{kV}$ range of $80 \mathrm{kVp}$ to $120 \mathrm{kVp}$. This represents most diagnostic x-ray beams used clinically and superficial therapy machines and has been used for various dosimetric procedures (Vuong et al 2003, Giles and Murphy 2002). This short note investigates the visible dye light absorption spectra for the relatively new Gafchromic XR type-T radiochromic film when exposed to low energy X-ray radiation.

\section{Materials and methods}

Gafchromic XR type-T radiochromic film (batch no K02b28XRT) was used for the visible absorption spectra study. For dose delivery, the films were positioned in a solid water (Constanitinou et al 1982) phantom of dimensions $30 \mathrm{~cm} \times 30 \mathrm{~cm} \times 30 \mathrm{~cm}$. The phantom was placed on a Pantak, Therapax 300DXT orthovoltage machine and doses ranging from 0 Gy to 8 Gy (using IAEA protocol) were given using a $100 \mathrm{kVp}(\mathrm{HVL}=3.5 \mathrm{~mm} \mathrm{Al}) \mathrm{x}$-ray beam with $3.1 \mathrm{~mm} \mathrm{Al}$ added filtration. The films were irradiated placed perpendicular to the central axis of the beam. Precautions in handling of radiochromic film outlined in TG-55 were used (Niroomand-Rad et al 1998). The film during storage and film analysis were kept in temperatures of $22{ }^{\circ} \mathrm{C} \pm 2{ }^{\circ} \mathrm{C}$ thus reducing the effects of time and temperature dependent evolution and readout (Meigooni et al 1996) of the absorption spectra of the film. The film is only removed from a light tight envelope during irradiation and readout to reduce any effects of ambient light (Butson et al 1998). The absorption spectra results were measured using a Shimadzu UV-160 UV-visible recording spectrophotometer (Butson et al 2002). Wavelength range of analysis was from $500 \mathrm{~nm}$ to $800 \mathrm{~nm}$ in $2 \mathrm{~nm}$ to $10 \mathrm{~nm}$ steps. The Shimadzu UV-160 has a spectral bandwidth of $3 \mathrm{~nm}$ with an accuracy of $\pm 0.5 \mathrm{~nm}$. The film was held in a quartz holding container. Spectra data were then analysed to calculate sensitivity values at various specific wavelengths and various band passes relating to various densitometry light sources.

\section{Results and discussion}

Figure 1 shows the absorption spectra for Gafchromic XR type-T film in the visible and partly into the infrared region $(500 \mathrm{~nm}$ to $800 \mathrm{~nm}$ ). Results are given for films ranging in applied doses of $0 \mathrm{cGy}$ to $800 \mathrm{cGy}$ produced by a $100 \mathrm{kVp}$ x-ray beam. As can be seen the absorption spectra for the film produce two pronounced peaks (as is the case for MD-55-2 and HS film) which shifts slightly to lower wavelengths with higher exposure levels. The peaks were located at $676 \mathrm{~nm}$ and $618 \mathrm{~nm}$ for 2 Gy absorbed dose and shifted to $662 \mathrm{~nm}$ and $612 \mathrm{~nm}$ for 8 Gy absorbed dose respectively. This represents a shift of $14 \mathrm{~nm}$ and $6 \mathrm{~nm}$ for the major and minor absorption peaks over this dose range. Also seen is the pronounced spectral band pass at approximately $520 \mathrm{~nm}$ to $550 \mathrm{~nm}$ produced by the coloured dye added to the film product to enhance the visual change in the films colour when irradiated. The added dye aids when comparing results to a visible calibration colour chart to help improve the accuracy of visual quantitative analysis as may be needed during fluoroscopic procedures.

Figure 2 shows the net optical density change for the same wavelengths for the XR type-T film. This is specifically the subtraction of our 0 Gy OD results from the exposed film OD. This highlights the changes in absorption spectra produced by irradiation with low energy $\mathrm{X}$-rays for this film type. A high sensitivity response is achievable with the film producing 


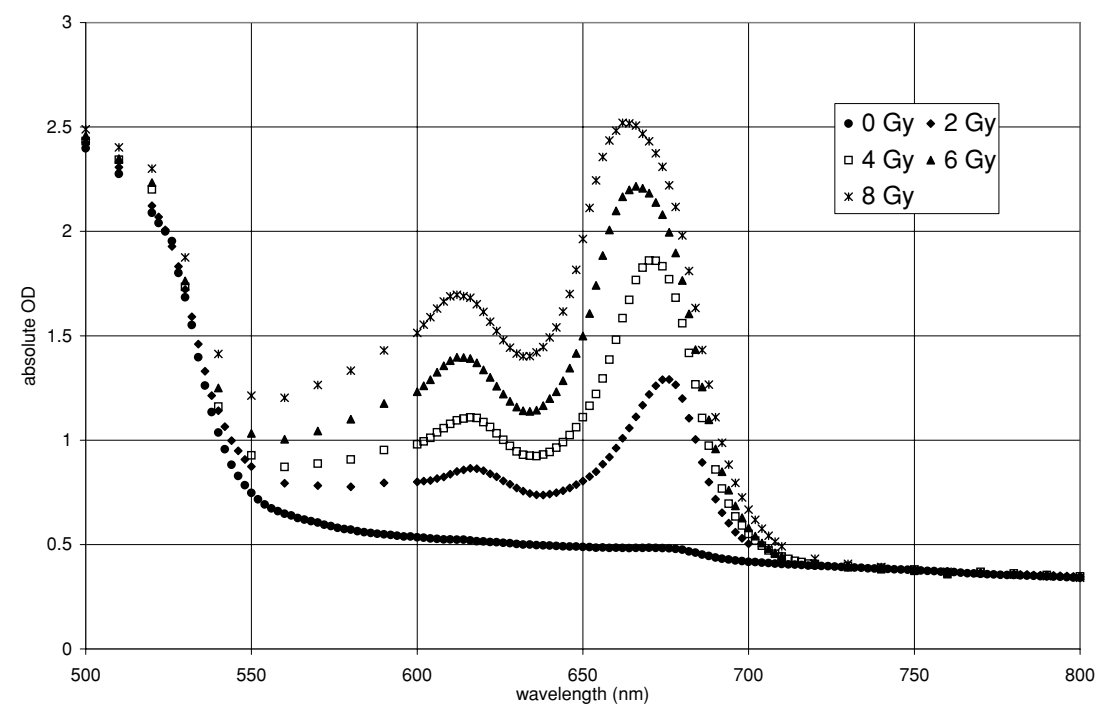

Figure 1. Visible absorption spectra for Gafchromic XR type-T radiochromic film when exposed to $100 \mathrm{kVp}$ x-rays. Of interest are the absorption peaks and the yellow dye band pass at approximately $520-550 \mathrm{~nm}$.

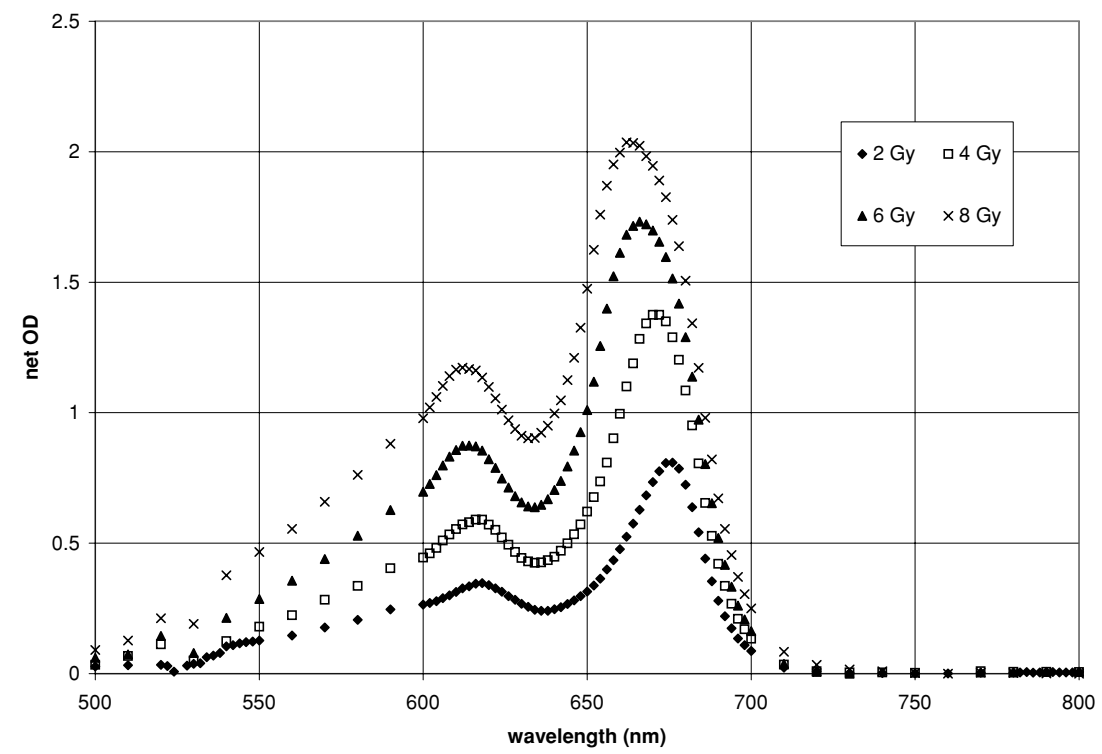

Figure 2. Net optical density change for Gafchromic XR type-T radiochromic film when exposed to low level doses of $100 \mathrm{kVp}$-rays.

an approximate change of $0.25 \mathrm{OD}$ per Gy at selected wavelengths. Various wavelengths of analysis are shown in more detail in figure 3 which is a comparison of dose sensitivity of the film when OD is measured at specific wavelengths or band passes. The highest sensitivity is accomplished at the nominal main absorption peak of $672 \mathrm{~nm}$. The linearity of results is slightly compromised due to the shift in the peak to lower wavelengths with increased dose, however, results are adequately modelled by a third-order polynomial $\left(R^{2}>0.99\right)$. If 


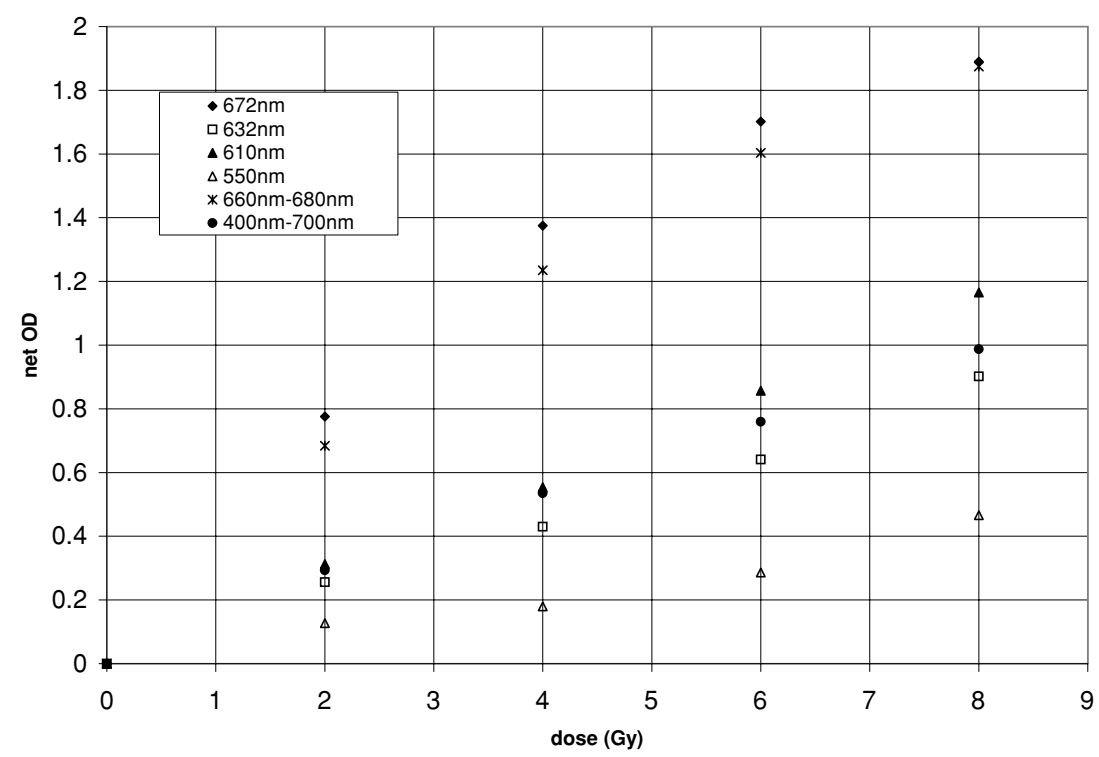

Figure 3. OD to dose sensitivity comparison for Gafchromic XR type-T radiochromic film when analysed at various wavelengths and band passes.

investigating the dose response with a band pass device such as a 'red' LED similar sensitivities are accomplished in the 660-680 $\mathrm{nm}$ average range with an increase in dose linearity. At other wavelengths such as $632 \mathrm{~nm}$ (same as HeNe laser) and fluorescent visible broad-band light sources the dose sensitivity decreases as analysis moves away from the absorption peaks but results also show a higher level of linearity.

\section{Conclusions}

Gafchromic XR type-T radiochromic film produces a visible light absorption spectrum with shifting nominal absorption peaks located at $676 \mathrm{~nm}$ for $2 \mathrm{~Gy}$ and $662 \mathrm{~nm}$ for $8 \mathrm{~Gy}$ absorbed dose for the main peak and $618 \mathrm{~nm}$ for $2 \mathrm{~Gy}$ and $612 \mathrm{~nm}$ for $8 \mathrm{~Gy}$ for the minor peak when exposed with $100 \mathrm{kVp}$ x-rays. The yellow dye introduced to the film produces a pronounced band pass at approximately $520 \mathrm{~nm}$ to $550 \mathrm{~nm}$ which changes the visible coloration (compared to other forms of Gafchromic film) of the film's dose response where the film changes from an unirradiated colour of yellow to a brown colour when irradiated.

\section{Acknowledgment}

This work has been fully supported by a grant from the Research Grants Council of HKSAR, China (project no CityU 100603).

\section{References}

Butson M J, Cheung T and Yu P K 2002 Corresponding dose response of radiographic film with layered gafchromic film Phys. Med. Biol. 47 N285-9

Butson M J, Yu K N, Cheung T and Metcalfe P E 2003 Radiochromic film for medical radiation dosimetry Mater. Sci. Eng. R 41 61-120 
Butson M, Yu P and Metcalfe P 1998 Effects of readout light sources and ambient light on radiochromic film Phys. Med. Biol. 43 2407-12

Constanitinou C, Attix F and Paliwal B 1982 A solid water phantom material for radiotherapy x-ray and gamma ray beam ray calculations Med. Phys. 9 436-41

Giles E R and Murphy P H 2002 Measuring skin dose with radiochromic dosimetry film in the cardiac catheterization laboratory Health Phys. 82 875-80

Meigooni, Sanders and Ibbott 1996 Dosimetric characteristics of an improved radiochromic film Med. Phys. 23 1883-8

Miller R B et al 2003 A high-power electron linear accelerator for food irradiation applications Nucl. Instrum. Methods Phys. Res. B 211 562-70

Niroomand-Rad A, Blackwell C, Coursey B, Gall K, Galvin J, McLaughlin W, Meigooni A, Nath R, Rodgers J and Soares C 1998 Radiochromic film dosimetry : recommendation of AAPM radiation therapy task group 55 Med. Phys. 25 2093-115

Vuong T, Devic S, Belliveau P, Muanza T and Hegyi G 2003 Contribution of conformal therapy in the treatment of anal canal carcinoma with combined chemotherapy and radiotherapy: results of a Phase II Int. J. Radiat. Oncol. Biol. Phys. 56 823-31

Young F C, Boller J R, Stephanakis S J, Jones T G and Neri J M 1999 Radiachromic film as a detector for intense $\mathrm{MeV}$ proton beams Rev. Sci. Instrum. 70 1201-4 